\title{
IMPORTANCE OF CULTURAL HERITAGE AND TOURISM EXPERIENCE OF GENERATION Z IN SERBIA
}

\author{
Jelena Stanković, \\ Slavko Alčaković, \\ Maja Obradović
}

Singidunum University, Belgrade, Serbia

Correspondence:

Jelena Stanković

e-mail:

jstankovic@singidunum.ac.rs

\begin{abstract}
:
Cultural heritage as element of tourism destination has a unique value in creating experience of tourist. This paper presents the results of the research towards the importance of cultural heritage when choosing a tourist destination by Generation Z in Serbia. The research was carried out in the form of an exploratory study on a sample of 50 respondents. The target group was demographic cohort Generation Z in Serbia as tourists. Generation Z differs from other generation cohorts predominantly in using of digital media and adopting new technologies. As «digital natives» they use digital media in everyday communication and other activities. They also use them in the decision-making process where to travel. In other words, they use digital media in order to get information about tourist sites, to purchase tourism services, as well as to share their travel experience. The aim of the research was to determine the influence of cultural heritage as a factor of decision making process and travel destination experience of Generation Z in Serbia.
\end{abstract}

Keywords:

digital media, Generation Z, tourist site, destination decision making

\section{INTRODUCTION}

Development of new technologies had significant impact on changing the use of media. Planning a trip, searching for the travel information, making a reservation and sharing experience about tourism destination become easier with the internet. When it comes to travel, travel planning has always been one of the main reasons for using the internet (Buhalis \& Jun, 2011).

The Internet as a travel planning tool shows different patterns of use across generations. As one of the demographic factors, age implies the division of consumers by their age. It is considered that the members of the same age cohorts have similar behavior, opinions and way of making decisions. The reason is that they are born in the same period of time and beside the years they have shared the life events through time. They existed in a certain period in cultural history shared important social and cultural events which affected on their behavior, thereby sharing views and worldview (Meehan, 2018).

Authors often use 1995 as the starting year for the Generation Z cohort. Members of the generation $\mathrm{Z}$ are the first generation which have not met the world without the internet and new mobile devices (Pater, 2018). 
Digital natives, as people call the generation $Z$, show different patterns of making decisions in the area of traveling. The youngest generations, such as generation $\mathrm{Z}$, are more active and engaged in travel planning by using variety of media platforms and devices for different activities (Xiang et al., 2015). Beside using their friends' suggestions and pictures placed on different platforms, they frequently use the opinion of social media influencers their experience when it comes to travel decisions making. Influencers on social networks are story tellers, who share unique story in collaboration with brands followers (Wong, 2018).

When it comes to travel making decisions, members of the generation $\mathrm{Z}$ are considered to be the generation that has a huge influence on family members. (Advance travel and tourism, 2018) Even though most of them are still young and not employed at this moment it is estimated that by the year 2020 it will present $40 \%$ of consumers with disposable income for travel (TilmaGroup, 2018). According to previous researches (TilmaGroup, 2018) some of the reasons for traveling of generation $\mathrm{Z}$ members are adventure and active experience, visiting unusual destinations, cultural involvement, learning and education, experience and visuals to share on social media.

Tourism destination does not have one common definition. Different authors use many ways to describe the essence of this term. A tourism destination is described as the location with a set of activities and related tourism facilities and services which tourists/ group of tourists chooses to visit; arena with different natural resources, different characteristics and attractions (McIntyre, 1993; Coltman, 1989). These elements are able to attract tourists/ visitors in a specific area (Popesku, 2009).

As mentioned, tourist destination implies the mix of different products and services. The essence of the tourist destination is not made up of individual attractions in themselves, but their combination shaped through the experience of tourist consumption (Popesku, 2009).

\section{CULTURAL HERITAGE}

As a tourism destination Serbia has a huge untapped potential for further development. From all of the factors that influence the creation of a competitive advantage of the tourism destination, in case of Serbia as a destination, only three elements provide positive effects- natural resources, historical and cultural heritage (Popesku, 2014).

Besides tourism destination, tourists, and consumption of experiences and products, cultural heritage presents the fourth pillar of contemporary cultural tourism (McKercher \& Cros, 2002).

International Council for Monuments and Sites (ICOMOS) defines cultural heritage as a broad concept which includes both tangible and intangible cultural assets (ICOMOS, 2018) Cultural heritage assets refer to history, education, architecture, music, aesthetics and design, tradition, as well as spiritual and religious characteristics and values of the particular country or region.

Tangible assets of cultural heritage refer to natural and cultural environment of a particular community, and encompass its cultural places and products. On the other hand, intangible assets of cultural heritage include people, their tradition, as well as the characteristics of folklore, religion, history, and popular culture. Intangible assets encompass a broader set of cultural heritage elements than tangible assets, creating the basis for further building and developing of cultural products and services of the particular community, country or a region. In other words, intangible assets include past and continuing cultural practices, knowledge, living experiences, and folklore and art collections, which create the basis for further cultural heritage development. In that respect, Principle 2.1 of the ICOMOS International Cultural Tourism Charter stresses out the importance of intangible heritage assets.

According to Principle 2.1, which manages the relationship between heritage places and tourism, the long term protection and conservation of intangible assets, such as heritage places, living cultures and collections, as well as their physical and ecological integrity and harmony in their environmental context, create an essential component of social, economic, political, cultural and tourism development of a community (ICOMOS, 2018). In addition to that, cultural heritage places and contents, as intangible assets, have an intrinsic value for all people, both tourist and local community residents, creating an important basis for cultural diversity and social development. 


\section{CULTURAL HERITAGE AND TOURISM EXPERIENCE}

Cultural heritage actively participates in creating unique tourism experience and value for the particular segment of tourists. Tourism experience is a set of memories based on individual tourist engagement, such as pleasant and memorable places and events, allowing tourists to build their own travel experiences so to satisfy a wide range of their personal needs, from pleasure to education and a search for meaning (Ramos et al., 2016). In tourism, experience is recognized as an important element of value created for tourists (Đorđević \& Zečević, 2015). Tourist experience has been created based on two criteria:

- active or passive participation when visiting tourism destination and its cultural heritage, and

- cognitive or affective participation when visiting tourism destination and its cultural heritage.

Based on Pine and Gilmore work on the significance of experience in consumption, tourists can gain their experience in an active or in a passive way (Pine \& Gilmore, 1999). Active tourist experiences include their direct participation in consuming elements of cultural heritage on the destination, which influences their impressions and memories. Such participations refer to active involvement in sport activities, tasting local food, learning language etc. Passive tourist experience implies the sense of satisfaction created on the tourism destination, without active participation of the tourist. Such experience is derived from visiting museums, cultural manifestations, concerts, or art galleries.

Depending on the cognitive participation, tourist experience can be based on: acceptation or an impression (Đorđević \& Zečević, 2015). Tourist experience based on acceptation is created when a tourist gains his or her experience of the destination by using active thinking and analyzing. For example, if the experience of visiting a museum is based on active thinking about the artifact, then it is an experience based on acceptation. On the other hand, tourist experience based on an impression is the results of the feelings and affection of the tourist. For instance, the experience of visiting a concert of contemporary music could be just the result of liking or disliking. In that case, the experience is based on an impression made by the music.

By combining two mentioned criteria, four different types of tourist experiences can be distinguished (Đorđević \& Zečević, 2015):

- Aesthetic experience presents the combination of passive and impressive tourist experience. It means that the tourist passively participates in experiencing cultural heritage, and reacts emotionally to it. Because of their architecture and design, visiting a new museum or concert buildings could be examples of aesthetic tourist experiences.

- Entertainment experience presents the combination of passive and acceptation experience. Tourist participation in sport activities organized by a local community or a hotel could be an example of entertainment experience.

- Escapist experience is based on an impression created by active tourist participation. The reasons for escapism could be different, such as the change of the place of residence, the escape from the everyday routine, search for fun, health or other needs. The tourist feels the need for an escape while actively participates in the creation of his or her experience.

- Education experience is based on acceptation created by active tourist participation. This form of tourist experience is typical for cultural tourism. It depends on active tourist participation in combination with thinking and analyzing cultural sites and cultural heritage on site, such as visiting ethnographic and anthropological characteristics of the tourism destination, learning local languages or dances.

Creating value for customers requires all four types of tourist experiences to be considered.

\section{METHODOLOGY}

The aim of the research was to determine factors that influence travel decisions, and whether cultural heritage influences the observed cohort in destination decision making and their travel destination experience. Participants filled in questionnaires which measured their attitude toward travel, factors that influence travel decisions, attitude toward the culture, and cultural heritage factors that influence destination travel and their online activities on and after the travelling, regarding its cultural attitude. 
Respondents who participated in this research were the members of Generations $\mathrm{Z}$ in total number of $(\mathrm{n}=50)$ : 15 (30\%) male and 35 (70\%) female, where 20 (40\%) were high school students and 30 (60\%) university students.

The online questionnaire was sent to the participants. The answer rate was $75 \%$. The research process was anonymous and lasts 7 minutes on average. The questionnaire had 3 parts: part 1 - demographics, part 2 travel factors, part 3 - culture attitude and travel destination experience.

\section{Travel factors (scale)}

The participants responded to five 5-point in Likert scales and were calculated using 5 scales (Negrusa \& Yolal, 2012): Learning scale was assessed by answers to the questions: "To broaden my general knowledge", "To prepare homework or a project", "Would contribute to my education", "It is important to visit cultural places", "To visit cultural places"; Culture scale was estimated by answering the questions: "To be with people with similar interests", "To experience cultural events and places", "I enjoy cultural places and events", "A specific interest in such attraction", "It is a part of my culture", "I felt that I should visit cultural places", "Because of its historic background"; Relaxation scale was estimated by answering the questions: "To get away from the demands of life", "To have a change from my daily routine", "To be with friends/family", "It is important to visit cultural places", "To spend my spare time", "To be emotionally involved", "I want to relax"; Pleasure-seeking and entertainment scale was estimated by answering the questions: "To be with other people who enjoy", "To tell friends about it", "I want to have some entertainment", "I want a day out"; Experience something new scale was estimated by answering the questions: "I was curious", "To experience new and different things", "It is stimulating and exciting", "I like the variety of things to see and do".

The five scales that measured travel factors (Table 1) all proved internally consistent within the present sample, where all Cronbach's alphas fall over Nunnally's (1970) criteria of .70.

Table 1. Reliability statistics for instruments: Learning scale, Culture scale, Relaxation scale, Pleasure-seeking and entertainment scale, Experience something new scale)

\begin{tabular}{lcc}
\hline \multicolumn{1}{c}{ Reliability statistics } & Cronbach's Alpha & $\mathrm{n}$ of items \\
\hline Learning scale & .84 & 5 \\
Culture scale & .82 & 7 \\
Pleasure-seeking and entertainment scale, Experience something new scale & .82 & 7 \\
Pleasure-seeking and entertainment scale & 74 & 4 \\
Experience something new scale & .88 & 4 \\
\hline
\end{tabular}

\section{RESULTS}

Research data show that the most important travel factor for Generation Z (Table 2) is the desire to experience something new $(\mathrm{M}=4.09, \mathrm{SD}=.94)$, culture is in the middle $(\mathrm{M}=3.53, \mathrm{SD}=.82)$ and the least important is to learn something about the destination $(\mathrm{M}=3.36, \mathrm{SD}=.99)$.

Table 2. Descriptive statistics for Travel factors (Learning, Culture, Relaxation, Pleasure-seeking and entertainment, Experience something new)

\begin{tabular}{lccccccc}
\hline Travel factors & $n$ & Min & Max & $M$ & SD & $z$ Skew & Kurt \\
\hline Learning & 50 & 1 & 5 & 3.36 & 0.99 & -0.61 & -0.16 \\
Culture & 50 & 2 & 5 & 3.53 & 0.82 & -0.37 & -0.76 \\
Relaxation & 50 & 1.71 & 5 & 3.92 & 0.84 & -0.88 & 0.46 \\
Pleasure-seeking and entertainment & 50 & 2 & 5 & 3.49 & 0.75 & 0.06 & -0.41 \\
Experience something new & 50 & 1.5 & 5 & 4.09 & 0.94 & -0.88 & -0.04 \\
\hline
\end{tabular}

Note. $\mathrm{n}$ - sample size, Min - minimum, Max - maximum, $M$ - Mean, SD - standard deviation, $z$ Skew - standardized skewness, $z$ Kurt - standardized kurtosis 
Overall attitude toward the culture for the respondents in this sample was $M=3.3$, where the respondents that are enrolled in high school have not too high level of attitude $(\mathrm{M}=3, \mathrm{SD}=1.03)$, and for $18-23$ is a little higher $(\mathrm{M}=3.43, \mathrm{SD}=.82)$.

For the members of Generation Z, the most important cultural and historical elements when choosing a tourist destination are Attractions $(\mathrm{M}=4.24, \mathrm{SD}=1.03)$, and Architecture $(\mathrm{M}=3, \mathrm{SD}=1.03)$, and the least important are Sports $(\mathrm{M}=3, \mathrm{SD}=1.03)$, and Theater $(\mathrm{M}=3, \mathrm{SD}=1.03)$,.

Table 3. Descriptive statistics elements for importance of cultural and historical places when choosing a tourist destination

\begin{tabular}{lccccccc}
\hline & $n$ & Min & Max & $M$ & SD & zSkew & $z$ Kurt \\
\hline Music & 50 & 1 & 5 & 3.36 & 1.51 & -0.5 & -1.15 \\
Sports & 50 & 1 & 5 & 2.82 & 1.52 & 0.21 & -1.34 \\
Food & 50 & 1 & 5 & 3.96 & 1.07 & -0.86 & 0.41 \\
Architecture & 50 & 1 & 5 & 4.2 & 1.09 & -1.41 & 1.45 \\
Events & 50 & 1 & 5 & 3.88 & 1.15 & -0.84 & 0.18 \\
Attractions & 50 & 2 & 5 & 4.24 & 0.87 & -0.88 & -0.09 \\
Design & 50 & 1 & 5 & 3.76 & 1.29 & -0.73 & -0.48 \\
Local people & 50 & 1 & 5 & 3.5 & 1.18 & -0.39 & -0.37 \\
Theatre & 50 & 1 & 5 & 2.86 & 1.23 & 0.07 & -0.91 \\
Museums & 50 & 1 & 5 & 3.72 & 1.33 & -0.87 & -0.44 \\
\hline
\end{tabular}

Note. $\mathrm{n}$ - sample size, Min - minimum, Max - maximum, $M$ - Mean, $S D$ - standard deviation, $z$ Skew - standardized skewness, $z$ Kurt - standardized kurtosis

It is important to note that the members of Generation $\mathrm{Z}$ plan to visit cultural and historical places (Table 4), but do not like to post content online about their experience.

Table 4. Descriptive statistics for online activities about the cultural experience on the tourist destination

\begin{tabular}{lccccccc}
\hline & $n$ & Min & Max & $M$ & SD & $z$ Skew & $z$ Kurt \\
\hline $\begin{array}{l}\text { In my travel plan, I always have a tour of cultural and } \\
\text { historical sites }\end{array}$ & 50 & 1 & 5 & 3,82 & 1,26 & $-0,55$ & $-0,94$ \\
$\begin{array}{l}\text { When I visit cultural and historical sites on a tourist } \\
\text { destination, I post some content on social networks }\end{array}$ & 50 & 1 & 5 & 2,46 & 1,36 & 0,57 & $-0,81$ \\
$\begin{array}{l}\text { When I am experiencing an entertaining travel experi- } \\
\text { ence, I put the content about it on social networks }\end{array}$ & 50 & 1 & 5 & 2,82 & 1,48 & 0,17 & $-1,30$ \\
\hline
\end{tabular}

Note. $\mathrm{n}$ - sample size, Min - minimum, Max - maximum, M - Mean, SD - standard deviation, $z$ Skew - standardized skewness, $z$ Kurt - standardized kurtosis

When asked if they comment anything on the social media or any type of travel website, respondents didn't show positive valance toward any type of online activity regarding cultural experience on the travel destination (Table 5), where for most of the questions, the answer was "I never do it". 
Table 5. Descriptive statistics for online activities about the cultural experience on the tourist destination

\begin{tabular}{|c|c|c|c|c|c|c|c|}
\hline & $n$ & Min & $\operatorname{Max}$ & $M$ & $S D$ & z Skew & $z$ Kurt \\
\hline $\begin{array}{l}\text { Comments on Booking.com, } \\
\text { Airbnb, Tripadvisor }\end{array}$ & 50 & 1 & 5 & 1,58 & 1,20 & 1,92 & 2,47 \\
\hline Comments on forums & 50 & 1 & 4 & 1,22 & 0,68 & 2,96 & 7,67 \\
\hline Vlog (Youtube, Vimeo and others) & 50 & 1 & 3 & 1,12 & 0,48 & 3,82 & 13,12 \\
\hline Blog & 50 & 1 & 3 & 1,08 & 0,40 & 4,84 & 22,33 \\
\hline
\end{tabular}

Note. $\mathrm{n}$ - sample size, Min - minimum, Max - maximum, M - Mean, SD - standard deviation, $z$ Skew - standardized skewness, $z$ Kurt - standardized kurtosis

\section{CONCLUSION}

The research was carried out in the form of an exploratory study on a sample of 50 respondents. The results showed that cultural heritage influences the Generation $\mathrm{Z}$ in the processes of destination decision making and their travel destination experience.

According to the results, respondents showed a significant overall attitude toward the culture especially when deciding where to travel based on suggestions coming from their peers and family members. The research also showed the overlapping of the results and the travel scale used as the research model: in both cases "experience" was highly rated travel factor, while "culture" was medium ranked. In both cases, "pleasure" was chosen as the least preferable of all the travel factors.

The respondents travel at least twice a year indicating culture as one of the highly significant travel factors. When choosing the travel destination, they showed notable interest in putting cultural heritage in their travel plans. As the most important cultural and historical elements on the destination the respondents selected "Attractions" and "Architecture". Based on the research results and according to the four different types of tourist experiences (Đorđević \& Zečević, 2015), it can be concluded that there is a high possibility that Generation $\mathrm{Z}$ members in Serbia develop aesthetic and education travel experience toward rather than entertainment and escapist experience on the destination.

Generation Z cohort in Serbia actively use new media (the internet, social media) in everyday communication. The results of the research showed that they do not share much about their travel experience after their visit of the destination. They do not tend to post comments of any kind, not even in forms of a blog, vlog or reviews.

\section{REFERENCES}

Advance travel and tourism. (2018). Advance travel and tourism. Retrieved September 16, from Gen Z travel trends: https:// www.advancetravelandtourism.com/gen-z-travel-trends/

Buhalis, D., \& Jun, S. H. (2011). E-tourism. Contemporary tourism reviews, 1, 2-38

Coltman, M. M. (1989). Tourism Marketing. New York: Van Nostrand Reinhold.

Đorđević, A., \& Zečević, B. (2015). Kreiranje vrednosti u turizmu. Beograd: Ekonomski fakultet, CID.

ICOMOS. (2018). International Cultural Tourism Charter- Managing Tourism at Places of Heritage Significance. Retrieved September 5, from https://www.icomos.org/charters/tourism_e.pdf

McIntyre, G. (1993). Sustainable tourism development: guide for local planners. Madrid: World Tourism Organization .

McKercher, B., \& Cros, H. D. (2002). Cultural Tourism: The Partnership Between Tourism and Cultural Heritage Management. New York: Routledge.

Meehan, M. (2018). Forbes. Retrieved September 15, from The Perfect Name For The Next Generation Of Americans: https://www.forbes.com/sites/marymeehan/2014/04/15/the-perfect-name-for-the-next-generation-of-americans /\#46c005a13416

Negrusa, A., \& Yolal, M. (2012). Cultural tourism motivation - the case of romanian youths. Annals of the University of Oradea, Economic Science Series, 21(1).

Pater, D. (2018). 10 Tips For Marketing To Gen Z Consumers. Retrieved September 8, from Forbes: https://www.forbes. com/sites/deeppatel/2017/05/01/10-tips-for-marketing-to-gen-Z-consumers/2/\#24ca62c86bb4 
Pine, J., \& Gilmore, J. (1999). The Experience Economy. Boston: Harvard Business School Press.

Popesku, J. (2009). Destinacijske menadžment organizacije kao oblik upravljanja razvojem turističkih destinacija. 1. Naučni skup sa međunarodnim učešćem Sinergija 2009. (pp. 253-256). Bijeljina: Univerzitet Sinergija.

Popesku, J. (2014). Social media as a tool of destination marketing organizations. SINTEZA 2014- E-Business in tourism and hospitality industry (pp. 715-721). Belgrade: Singidunum University.

Ramos, C., Henriques, C., \& Lanquar, R. (2016). Augmented Reality for Smart Tourism in Religious Heritage Itineraries: Tourism Experiences in the Technological Age. IGI Global.

TilmaGroup. (2018). TilmaGroup. Retrieved September 18, from GEN Z WILL INFLUENCE 40\% OF TRAVEL BY 2020!: https://www.tilmagroup.com.au/blogtilma/2017/8/21/gen-Z-will-influence-40-of-travel-by-2020

Wong, K. (2018). Forbes. Retrieved September 16, from How Millennials and Gen Z Transformed Tourism Marketing Through Sharing: https://www.forbes.com/sites/kylewong/2016/12/13/how-millennials-and-gen-z-transformedtourism-marketing-through-sharing/\#66cf49c52868

Xiang, Z., Magnini, V. P., \& Fesenmaier, D. R. (2015). Information technology and consumer behavior in travel and tourism: Insights from travel planning using the internet. Journal of Retailing and Consumer Services, 244-249. doi:10.1016/j.jretconser.2014.08.005 